\title{
Genetic Profile of Patients with Classical Ph-negative Chronic Myeloproliferative Diseases in the Republic of Sakha (Yakutia)
}

\author{
Tuiara N. Aleksandrova ${ }^{1,2^{*}}$; Nadezhda I. Pavlova, $\mathrm{PhD}^{1}$; Khariton A. Kurtanov, $\mathrm{PhD}^{1}$; \\ Inna I. Mulina ${ }^{2}$; Vera N. Yadrikinskaya ${ }^{3}$; Lena D. Terekhova ${ }^{2}$; Irina E. Solovieva ${ }^{2}$; \\ Aleksandra T. Diakonova ${ }^{1}$; Natalia A. Solovyeva, $\mathrm{PhD}^{1}$ \\ ${ }^{1} Y a k u t$ Science Center of Complex Medical Problems \\ ${ }^{2}$ Republic Hospital No. 1 - National Center of Medicine of the Republic of Sakha (Yakutia) \\ ${ }^{3}$ M. K. Ammosov North-Eastern Federal University \\ Yakutsk, the Russian Federation
}

\begin{abstract}
Background: Mutations in the $J A K 2, C A L R$, and $M P L$ genes are key factors of the classical Ph-negative CMPD pathogenesis with demonstrated diagnostic and prognostic value. The aim of this research was to study the prevalence of $J A K 2, C A L R$, and $M P L$ mutations in patients with CMPD and healthy individuals in the Republic of Sakha (Yakutia) (RS(Y)).

Methods and Results: The study included patients with previously confirmed diagnoses of PV ( $\mathrm{n}=15), \mathrm{ET}(\mathrm{n}=16)$, and PMF $(\mathrm{n}=11)$ and 68 people with peripheral blood changes, suspected to have CMPD. The control group included 184 healthy volunteers. All patients and participants in the control group were genotyped according to the following SNPs: the JAK2 rs77375493 SNP, the CALR rs765476509 SNP, the CALR rs 1450785140 SNP, the MPL rs121913616 SNP, and the MPL rs121913615. The prevalence of the $J A K 2 \mathrm{~V} 617 \mathrm{~F}$ mutation among PV patients in the RS(Y) was $90.9 \%$. Patients with ET in $61.3 \%$ of cases were carriers of the $J A K 2 \mathrm{~V} 617 \mathrm{~F}$ mutation, in $6.4 \%$ of $C A L R$ mutations, and in $3.2 \%$ of the MPLW515L mutations. In PMF patients, the $J A K 2 \mathrm{~V} 617 \mathrm{~F}$ mutation was detected in $64.7 \%$ of cases, and the Type 1 CALR mutation was detected in $17.6 \%$ of cases. Carriage of the $J A K 2 \mathrm{~V} 617 \mathrm{~F}$ mutation was revealed in $1.1 \%$ of healthy individuals and in $4.4 \%$ of individuals with initial signs of a myeloproliferative process.

Conclusion: Early molecular genetic testing will improve the timely diagnosis of CMPD and possibly reduce the number of complications. (International Journal of Biomedicine. 2020;10(1):54-57.)
\end{abstract}

Key Words: chronic myeloproliferative diseases $\bullet$ gene $\bullet$ mutations $\bullet$ single nucleotide polymorphism

\section{Abbreviations}

AS-PCR, allele-specific polymerase chain reaction; CMPD, chronic myeloproliferative diseases; CALR, Calreticulin; ET, essential thrombocythemia; PV, polycythemia vera; PMF, primary myelofibrosis; SNPs, single nucleotide polymorphisms

\section{Introduction}

Recent decades have been marked by a major breakthrough in understanding of the classical Ph-negative CMPD pathogenesis. In 2005, a sense mutation V617F (also

*Corresponding author: Tuiara Aleksandrova, Yakut Science Center of Complex Medical Problems. Yakutsk, the Republic of Sakha (Yakutia),Russia.E-mail: alexandrova_tuyara@mail.ru known as $J A K 2 \mathrm{Val617Phe)}$ at exon 14 of the Janus Kinase (JAK)2 gene (a valine-to-phenylalanine substitution in position 617) was described. This mutation can also be described using the SNP ID rs77375493 (the wild-type (normal) allele is rs77375493(G), and the (very rare) variant allele is rs77375493(T)). The mutation results in loss of autoinhibition of JAK2 tyrosine kinase, its hyperactivation and cytokine-independent differentiation of myeloid cells. ${ }^{(1)} \mathrm{A}$ little later, mutations in the MPL, CALR genes were described, 
which play a key role in the pathogenesis of megakaryocyte proliferation. Among mutations in the MPL gene encoding the thrombopoietin receptor, mutations W515L (a tryptophan-toleucine substitution in position 515) and W515K (a tryptophanto-lysine substitution in position 515) have a major clinical importance. $^{(2)}$ They lead to spontaneous activation of the MPL receptor and increase its sensitivity to thrombopoietin. The role of CALR mutations, in particular, Type 1 (52-bp deletion; p.L367fs*46) mutation and Type 2 (5-bp TTGTC insertion; p.K385fs*47) mutation, include the loss of KDEL signal sequence due to a shift of the reading frame by 1 nucleotide. ${ }^{(3)}$

The diagnostic value of the $J A K 2, C A L R$, and $M P L$ mutations has been determined; they are included in the WHO criteria for the diagnosis of classical Ph-negative CMPD. ${ }^{(4)}$ In addition, many studies have been published that describe the impact of mutational status on the clinical course, the risk of complications, and disease outcome. ${ }^{(5)}$ Despite the progress, the problem of early diagnosis of diseases and the prevention of thrombotic complications remains unresolved. According to findings in the literature, at the time of diagnosis thrombotic complications are recorded in $12 \%-39 \%$ of PV patients, $7.14 \%$ $26.3 \%$ of ET patients and $4 \%-7 \%$ of PMF patients. ${ }^{(6)}$ In recent years, we have been getting more information about the prevalence of the JAK2 V617F mutation among individuals with thrombosis of different localization. In addition, the observed frequency of the JAK2 (0.3\%-3.1\%) and CALR (0.16\%) gene mutations among healthy populations in different countries exceeds the officially recorded incidence of chronic myeloid neoplasm $(0.002 \%$ $0.02 \%){ }^{(7,8)}$ In this regard, the JAK2V617F mutation may be an early diagnostic criterion for identifying individuals with latent clonal hematopoiesis of the myeloid germline, and the role of the $C A L R$ and $M P L$ mutations remains unclear.

The aim of this research was to study the prevalence of $J A K 2, C A L R$, and $M P L$ mutations in patients with CMPD and healthy individuals in the $\mathrm{RS}(\mathrm{Y})$.

\section{Materials and Methods}

The study included patients with previously confirmed diagnoses of PV $(n=15)$, ET $(n=16)$, and PMF $(n=11)$ and 68 people with peripheral blood changes, suspected to have CMPD. All patients underwent outpatient consultation in the Republican Hospital №1 "National Center of Medicine"; the diagnosis was verified based on WHO diagnostic criteria valid at the time of diagnosis. ${ }^{(4)}$ The control group included 184 healthy volunteers.

The study was approved by the Ethics Committee of the Yakut Science Center of Complex Medical Problems (YSC CMP). Written informed consent was obtained from each research participant.

The average age of patients ranged from 50 to 60 years: $52 \pm 16.63$ for ET, $60 \pm 12.84$ for PV, and $50 \pm 21.17$ for PMF. In all investigated subgroups of patients, women predominated (80.6\% in ET, 54.5\% in PV and 52.9\% in PMF). Further analysis of ethnic groups demonstrated a predominance of Yakuts among ET patients (67.7\%) and Russians among patients with PV and PMF (54.5\% and 52.9\%, respectively). The median follow-up time was 48 months (from 0 to 252 months).

The experimental part of the work was carried out in the Department of Molecular Genetics at YSC CMP. All patients and participants in the control group were genotyped according to the following SNPs: the JAK2 rs 77375493 SNP, the CALR rs765476509 SNP, the CALR rs1450785140 SNP, the $M P L$ rs121913616 SNP, and the MPL rs121913615.

DNA was isolated from peripheral blood lymphocytes with a commercial DNA-isolation kit (Excell Biotech Corporation; Yakutsk, Russia). SNP was determined using AS-PCR. Amplification of the gene region containing the polymorphic variant was carried out using standard pairs of primers produced by SybEnzime (Novosibirsk, Russia). ${ }^{(9-11)}$ Primer sequences and conditions for amplification are presented in Table 1.

Table 1.

Primers and conditions for PCR

\begin{tabular}{|c|c|c|c|}
\hline SNP & Primers & Amplicon length & $\begin{array}{l}\text { Annealing } \\
\text { temperature }\end{array}$ \\
\hline \multirow{3}{*}{$\begin{array}{l}J A K 2 \\
\text { rs77375493 }\end{array}$} & $\begin{array}{l}\text { Forward mutant-specific } \\
\text { 5'-AGCATTTGGTTTTAAATTATGGAGTATATT-3' }\end{array}$ & \multirow{3}{*}{$\begin{array}{l}\text { Allele } T- \\
364 \text { bp and } 203 \text { bp } \\
\text { Allele } \mathrm{G}-364 \text { bp }\end{array}$} & \multirow{3}{*}{$56^{\circ} \mathrm{C}$} \\
\hline & $\begin{array}{l}\text { Forward } \\
\text { 5'-ATCTATAGTCATGCTGAAAGTAGGAGAAAG-3' }\end{array}$ & & \\
\hline & $\begin{array}{l}\text { Reverse } \\
\text { 5'-CTGACACCTAGCTGTGATCCTG-3' }\end{array}$ & & \\
\hline \multirow{4}{*}{$\begin{array}{l}\text { MPL } \\
\text { rs121913616 } \\
\text { rs121913615 }\end{array}$} & $\begin{array}{l}\text { Forward } \\
\text { 5'-GCCGAAGTCTGACCCTTTTT-3' }\end{array}$ & \multirow{4}{*}{$\begin{array}{l}\text { Wild-type }-209 \text { bp } \\
\text { Mutation W515L-124bp } \\
\text { Mutation W515K - } 125 \text { bp }\end{array}$} & \multirow{4}{*}{$55^{\circ} \mathrm{C}$} \\
\hline & $\begin{array}{l}\text { Reverse } \\
\text { 5'-ACAGAGCGAACCAAGAATGCCTGTTTACA-3' }\end{array}$ & & \\
\hline & $\begin{array}{l}\text { Forward mutant-specific for W515L } \\
\text { 5'-GGCCTGCTGCTGCTGAAGTT-3' }\end{array}$ & & \\
\hline & $\begin{array}{l}\text { Reverse mutant-specific for W515K } \\
\text { 5'-TGTAGTGTGCAGGAAACTGCTT-3' }\end{array}$ & & \\
\hline $\begin{array}{l}\text { CALR } \\
\text { rs } 765476509 \\
\text { rs } 1450785140\end{array}$ & $\begin{array}{l}\text { Forward } 1 \\
\text { 5'-GCAGCAGAGAAACAAATGAAGG-3' } \\
\text { Forward } 2 \\
\text { 5'-GCAGAGGACAATTGTCGG-3' } \\
\text { Reverse } \\
\text { 5'-AGAGTGGAGGAGGGGAACAA-3' }\end{array}$ & $\begin{array}{l}\text { Wild-type }-357 \mathrm{bp} \\
\text { Type } 1 \text { mutation }-302 \mathrm{bp} \\
\text { Type } 2 \text { mutation }-272 \mathrm{bp}\end{array}$ & $56^{\circ} \mathrm{C}$ \\
\hline
\end{tabular}


Detection of PCR products was carried out on a $3 \%$ agarose gel stained with ethidium bromide using a standard Tris-acetate buffer at $120 \mathrm{~V}$ for 45 minutes.

Statistical analysis was performed using Microsoft Excel 2010. For descriptive analysis, results are presented as mean \pm standard deviation (SD). The Mann-Whitney U Test was used to compare the differences between the two independent groups. Differences in the allele distribution between the two groups were assessed by $\chi 2$ - test with Yates correction. Odds ratios (ORs) and 95\% confidence intervals (CIs) were calculated. A probability value of $P<0.05$ was considered statistically significant.

\section{Results and Discussion}

According to the results of genotyping studied groups, the $\mathrm{T}$ allele of the $J A K 2 \mathrm{~V} 617 \mathrm{~F}$ mutation was detected in $48.2 \%$ of patients and $1.1 \%$ of healthy individuals. Mutations in the CALR gene were detected in $4.5 \%$ of patients, of which $3.6 \%$ had a mutation of Type 1 , and $0.9 \%$ had a mutation of Type 2. Mutations in the MPL gene were detected in $1.8 \%$ of patients. Among the healthy group, mutations in the CALR and $M P L$ genes were not detected (Table 2).

Table 2.

Prevalence of JAK2, CALR, MPL mutations in patients and control group

\begin{tabular}{|c|c|c|c|c|}
\hline $\begin{array}{l}\text { Alleles/ } \\
\text { Type of } \\
\text { mutation }\end{array}$ & $\begin{array}{c}\text { Patients } \\
(\mathrm{n}=110) \\
\%\end{array}$ & $\begin{array}{c}\text { Control } \\
(\mathrm{n}=184) \\
\%\end{array}$ & $x^{2}$ & $\begin{array}{c}\text { OR }(95 \% \mathrm{CI}) \\
P\end{array}$ \\
\hline \multicolumn{5}{|c|}{$J A K 2$} \\
\hline $\mathrm{T}$ & $48.2)$ & 1.1 & \multirow{2}{*}{197.7} & \multirow{2}{*}{$\begin{array}{c}84.614(30.504-234.708) \\
P=0.000\end{array}$} \\
\hline G & 51.8 & 98.9 & & \\
\hline \multicolumn{5}{|c|}{ CALR } \\
\hline Wild-type & 95.4 & 100 & \multirow{3}{*}{6.007} & \multirow{3}{*}{$P=0.015$} \\
\hline 1 type mutation & 3.6 & 0 & & \\
\hline 2 type mutation & 0.9 & 0 & & \\
\hline \multicolumn{5}{|c|}{$M P L$} \\
\hline Wild-type & 98.2 & 100 & \multirow{3}{*}{1.215} & \multirow{3}{*}{$P=0.271$} \\
\hline $\begin{array}{l}\text { W515L } \\
\text { mutation }\end{array}$ & 1,8 & 0 & & \\
\hline $\begin{array}{l}\text { W515K } \\
\text { mutation }\end{array}$ & 0 & 0 & & \\
\hline
\end{tabular}

The genetic profiles of patients with verified diagnoses $(\mathrm{n}=70)$ demonstrated that PV patients in $90.9 \%$ of cases carry the $J A K 2 \mathrm{~V} 617 \mathrm{~F}$ mutation. Among ET patients the $J A K 2 \mathrm{~V} 617 \mathrm{~F}$ mutation was detected in $61.3 \%$ of cases, CALR mutations in $6.4 \%$, and $M P L$ mutation in $3.2 \%$. PMF patients were carriers of the $J A K 2 \mathrm{~V} 617 \mathrm{~F}$ mutation in $64.7 \%$ of cases, and CALR mutations in $17.6 \%$ of cases (Table 3). Mutations in the CALR and MPL genes were found in patients with PV. In $3 J A K 2 \mathrm{~V} 617 \mathrm{~F}$-positive young patients $(24,29$, and 33 years old) with borderline changes in the peripheral blood count, clinical and laboratory parameters did not meet the criteria for the diagnosis of CMPD; therefore, they were recommended for dynamic follow-up.
Table 3.

Prevalence of JAK2, MPL, CALR mutations in patients with CMPD

\begin{tabular}{|c|c|c|c|}
\hline Mutation & $\begin{array}{c}\mathrm{PV}, \mathrm{n}=22 \\
\%\end{array}$ & $\begin{array}{c}\text { ET, } n=31 \\
\%\end{array}$ & $\begin{array}{c}\text { PMF, } \mathrm{n}=17 \\
\%\end{array}$ \\
\hline JAK2V617F & 90.9 & 61.3 & 64.7 \\
\hline$C A L R$, total & 0 & 6.4 & 17.6 \\
\hline CALR Type 1 & 0 & 3.2 & 0 \\
\hline CALR Type 2 & 0 & 3.2 & 17.6 \\
\hline$M P L$, total & 0 & 3.2 & 0 \\
\hline
\end{tabular}

Next, we evaluated the impact of the JAK2V617F mutation in clinical presentation of patients with ET and PMF. It was found that the average age of the $J A K 2 \mathrm{~V} 617 \mathrm{~F}$ (T allele)positive ET patients was significantly higher than that of carriers of the wild-type $\mathrm{G}$ allele (58.9 \pm 13.25 and $44.3 \pm 16.33$, $P<0.05$ ) (Table 4). In patients with PMF, the JAK2V617F(T allele)-positive individuals demonstrated a higher level of leukocytosis $\left(20.2 \times 10^{9} \pm 11.01\right.$ vs $\left.10.2 \times 10^{9} \pm 6.24, P<0.05\right)$.

\section{Table 4.}

The JAK2V617F mutation and clinical presentation of patients with ET and PMF

\begin{tabular}{|c|c|c|c|c|c|c|}
\hline \multirow[b]{2}{*}{ Variable } & \multicolumn{3}{|c|}{$\operatorname{ET}(n=31)$} & \multicolumn{3}{|c|}{$\operatorname{PMF}(n=17)$} \\
\hline & $\begin{array}{c}\text { JAK2V617F } \\
\text { positive }\end{array}$ & $\begin{array}{c}\text { JAK2V617F } \\
\text { negative }\end{array}$ & $P$ & $\begin{array}{c}\text { JAK2V617F } \\
\text { positive }\end{array}$ & $\begin{array}{c}\text { JAK2V617F } \\
\text { negative }\end{array}$ & $P$ \\
\hline Age, yrs & $58.9 \pm 13.25$ & $44.3 \pm 16.33$ & $<0.05$ & $54 \pm 16.95$ & $54 \pm 15.39$ & $>0.05$ \\
\hline $\begin{array}{l}\mathrm{RBC}, \\
\times 10^{12} / \mathrm{L}\end{array}$ & $4.8 \pm 1.03$ & $4.6 \pm 0.89$ & $>0.05$ & $5.1 \pm 1.47$ & $4.0 \pm 0.96$ & $>0.05$ \\
\hline $\begin{array}{l}\mathrm{Hb}, \\
\mathrm{g} / \mathrm{L}\end{array}$ & $130 \pm 20.94$ & $140 \pm 22.75$ & $>0.05$ & $125 \pm 26.59$ & $125 \pm 30.98$ & $>0.05$ \\
\hline $\begin{array}{l}\text { Hct, } \\
\%\end{array}$ & $39.9 \pm 6.65$ & $42.5 \pm 6.13$ & $>0.05$ & $40.2 \pm 9.26$ & $38.9 \pm 8.06$ & $>0.05$ \\
\hline $\begin{array}{l}\text { WBC, } \\
\times 10^{9} / \mathrm{L}\end{array}$ & $9.2 \pm 4.26$ & $11.2 \pm 9.40$ & $>0.05$ & $20.2 \pm 11.01$ & $10.2 \pm 6.24$ & $<0.05$ \\
\hline $\begin{array}{l}\text { Platelets } \\
\times 10^{9} / \mathrm{L}\end{array}$ & $934.4 \pm 278.3$ & $940.9 \pm 172.9$ & $>0.05$ & $868 \pm 576.21$ & $671.8 \pm 577.9$ & $>0.05$ \\
\hline $\begin{array}{l}\text { Spleen, } \\
\mathrm{cm}^{2}\end{array}$ & $42.1 \pm 21.2$ & $40.4 \pm 17.60$ & $>0.05$ & $60 \pm 31.23$ & $103.2 \pm 64.83$ & $>0.05$ \\
\hline
\end{tabular}

RBC - Red Blood Cells; Hb - Hemoglobin; Hct - Hematocrit; WBC- -White Blood Cells

Our results are comparable with well-known data and confirm the diagnostic value of genetic testing. According to the results of numerous studies, the prevalence of the $J A K 2 \mathrm{~V} 617 \mathrm{~F}$ mutation among patients with $\mathrm{PV}$ is more than 95\%, with ET and PMF - 60\%. Among patients with ET and PMF, CALR mutations were detected in $20 \%-25 \%$ of cases, $M P L$ in $5 \%$, and triple-negative status in $5 \%-10 \%{ }^{(12)}$

In clinical practice, mutations in the $J A K 2, C A L R$, and $M P L$ genes play a role in predicting the clinical course of diseases and stratifying the risk of thrombotic complications. The JAK2V617F mutation is known to significantly increase the risk of thrombotic complications among patients with ET and PMF. The JAK2V617F-positive patients with ET are primarily among the elderly. They are characterized 
by a high level of hemoglobin, leukocytosis and moderate thrombocytosis. Extreme trombocytosis, a lower risk of thrombotic complications and a high risk of transformation into secondary myelofibrosis are characteristic of CALR mutation-positive patients. In cases of PMF, patients with the $J A K 2 \mathrm{~V} 617 \mathrm{~F}$ mutation have a worse prognosis than those with the CALR mutation. Leukocytosis and a lower incidence of severe anemia is common for $J A K 2 \mathrm{~V} 617 \mathrm{~F}$-positive PMF patients. $^{(13)}$

The results of numerous epidemiological studies that include patients with thrombosis at different sites led to the hypothesis that the $J A K 2 \mathrm{~V} 617 \mathrm{~F}$ mutation can be used as a universal marker of thrombogenic risk in various clinical conditions. $^{(14)}$ A high prevalence of mutation was observed among individuals with cerebral vascular thrombosis $(3.8 \%-$ $6.6 \%$ ), splanchnic vein thrombosis $(16 \%)$, and Budd-Chiari syndrome (up to $40 \%$ ). ${ }^{(7)}$ A screening study of Russian donors revealed carriage of the $J A K 2 \mathrm{~V} 617 \mathrm{~F}$ mutation in $0.65 \%$ of cases, and the highest frequency was recorded in the Danish population $-3.1 \% .^{(7,8)}$ Long-term monitoring of mutation carriers has demonstrated that the JAK2V617F-positive individuals have a higher risk of developing not only myeloid neoplasms, but also solid tumors. ${ }^{(15)}$

In conclusion: The prevalence of the JAK2V617F mutation among PV patients in the RS(Y) was $90.9 \%$. Patients with ET in $61.3 \%$ of cases were carriers of the $J A K 2 \mathrm{~V} 617 \mathrm{~F}$ mutation, in $6.4 \%$ of $C A L R$ mutations, and in $3.2 \%$ of the MPLW515L mutations. In PMF patients, the JAK2V617F mutation was detected in $64.7 \%$ of cases, and the Type 1 CALR mutation was detected in $17.6 \%$ of cases. Carriage of the $J A K 2 \mathrm{~V} 617 \mathrm{~F}$ mutation was revealed in $1.1 \%$ of healthy individuals and in $4.4 \%$ of individuals with initial signs of a myeloproliferative process. The results of clinical evaluation demonstrated that the $J A K 2 \mathrm{~V} 617 \mathrm{~F}$ mutation affects disease phenotype. For the $J A K 2 \mathrm{~V} 617 \mathrm{~F}$-positive ET patients, disease manifestation in older age is characteristic, and in the case of PMF, the JAK2V617F mutation was associated with higher leukocytosis. Early molecular genetic testing will improve the timely diagnosis of CMPD and possibly reduce the number of complications.

\section{Acknowledgments}

The study was carried out within the framework of the project "The study of the genetic structure and burden of hereditary pathology of populations of the Republic of Sakha (Yakutia), using the Unique scientific equipment (USE) "The Genome of Yakutia" (Reg. No. USU_507512).

\section{Competing Interests} interests.

The authors declare that they have no competing

\section{References}

1. De Freitas RM, da Costa Maranduba CM. Myeloproliferative neoplasms and the JAK/STAT signaling pathway: an overview. Rev Bras Hematol Hemoter. 2015;37(5):348-53. doi:10.1016/j.bjhh.2014.10.001.

2. Langabeer SE, Andrikovics H, Asp J, Bellosillo B, Carillo S, Haslam K, et al.; MPN\&MPNr-EuroNet. Molecular diagnostic of myeloproliferative neoplasms. Eur J Haematol. 2015;95(4):270-9. doi: 10.1111/ejh.12578.

3. Silyutina AA, Gin II, Matyukhina NM, Balayan EN, Butylin PA. [Myelofibrosis Models: Literature Review and Own Data]. Clinical Oncohematology. 2017;10(1):75-84 doi: 10.21320/2500-2139-2017-10-1-75-84. [Article in Russian].

4. Arber DA, Orazi A, Hasserjian R, Thiele J, Borowith MJ, Le Beau MM, et al. The 2016 revision to the World Health Organization classification of myeloid neoplasms and acute leukemia. Blood. 2016;127(20):2391-2405.

5. Melikyan AL, Subortseva IN. [Biology of myeloproliferative malignancies]. Clinical Oncohematology. 2016;9(3):314-25. doi: 10.21320/2500-2139-2016-9-3-314325. [Article in Russian].

6. Shikhbabaeva DI, Polushkina LB, Shuvaev VA, Martynkevich IS, Kapustin SI, Zamotina TB, et al. [Genetic markers of hereditary thrombophilia and risk of thrombotic complications in patients with polycythemia vera]. Clinical Oncohematology. 2017;10(1):85-92. doi: 10.21320/25002139-2017-10-1-85-92. [Article in Russian].

7. Olkhovskiy IA, Filina NG, Gorbenko AS, Stolyar MA, Kolotvina TB, Subbotina TN. [Prevalence of mutations in JAK2 among blood donors]. Russian Journal of Hematology and Transfusiology. 2018;63(1):65-70. doi: 10.25837/ HAT.2018.49..1..006. [Article in Russian].

8. Cordua S, Kjaer L, Skov V, Pallisgaard N, Hasselbalch HC, Ellervik C. Prevalence and phenotypes of JAK2 V617F and calreticulin mutations in a Danish general population. Blood. 2019;134(5):469-479. doi: 10.1182/ blood.2019002756

9. Shepard GC, Lawson HL, Hawkins GA, Owen J. BsaXI/ RFLP analysis of initial or selectively reamplified PCR product is unreliable in detecting the V617F mutation in JAK2. Int J Lab Hematol. 2010;33(3):267-71. doi: 10.1111/j.1751553X.2010.01282.x

10. Jeong JH, Te Lee H, Seo JY, Seo YH, Kim KH, Kim MJ. Screening PCR Versus Sanger Sequencing: Detection of CALR Mutations in Patients With Thrombocytosis. Ann Lab Med. 2016;36(4):291-9. doi: 10.3343\%2Falm.2016.36.4.291. 11. Chi J, Pierides Ch, Mitsidou A, Miltiadou A, Gerasimou P, Nicolaou K et al. A sensitive detection method for MPLW515L or MPLW515K mutation in myeloproliferative disorders. European Journal of Experimental Biology. 2014;4(5):33-36. 12. Silvennoinen O, Hubbard SR. Molecular insights into regulation of JAK2 in myeloproliferative neoplasms. Blood. 2015;125(22):3388-92. doi: 10.1182/blood-2015-01-621110

13. Rumi E, Cazzola M. Diagnosis, risk stratification, and response evaluation in classical myeloproliferative neoplasms. Blood. 2017;129(6):680-692. doi: 10.1182/ blood-2016-10-695957

14. Nielsen C, Birgens HS, Nordestgaard BG, Bojesen SE. Diagnostic value of JAK2 V617F somatic mutation for myeloproliferative cancer in 49488 individuals from the general population. Br J Haematol. 2013;160(1):70-9. doi: 10.1111/bjh.12099

15. Nielsen C, Birgens HS, Nordestgaard BG, Kjaer L, Bojesen SE. The JAK2 V617F somatic mutation, mortality and cancer risk in the general population. Haematologica. 2011;96(3):4503. doi: 10.3324/haematol.2010.033191. 